\title{
The influence of high-resolution wind stress field on the power input to near-inertial motions in the ocean
}

\author{
Antonija Rimac, ${ }^{1,2}$ Jin-Song von Storch, ${ }^{1}$ Carsten Eden, ${ }^{3}$ and Helmuth Haak ${ }^{1}$ \\ Received 22 July 2013; revised 29 August 2013; accepted 4 September 2013; published 23 September 2013.
}

[1] The wind power input to near-inertial (NI) motions is studied using a global eddy-permitting ocean general circulation model. The model is forced by high- (1-hourly, at $0.35^{\circ}$ resolution) and low-resolution (6-hourly, at $1.875^{\circ}$ resolution) wind data. A change from low- to high-resolution forcing results in an increase in NI kinetic energy by a factor three and raises the wind-generated power input to NI motions from $0.3 \mathrm{TW}$ to $1.1 \mathrm{TW}$. Time and space filtering of the wind fields yield less kinetic energy, with a larger drop from time filtering. This strong sensitivity to wind forcing points to a possible underestimation of the wind-generated energy available for deep ocean mixing in previous studies based on low-resolution winds. Citation: Rimac, A., J.-S. von Storch, C. Eden, and H. Haak (2013), The influence of high-resolution wind stress field on the power input to near-inertial motions in the ocean, Geophys. Res. Lett., 40, 4882-4886, doi:10.1002/grl.50929.

\section{Introduction}

[2] It has long been known that the ocean kinetic energy spectrum reveals a pronounced maximum near the inertial frequency [e.g., Munk, 1981]. The near-inertial (NI) waves are excited by winds and are an important source for oceanic mixing. About 2 TW of power input, mainly supplied by winds and tides, are required for mixing to sustain the global general circulation in the ocean [Munk and Wunsch, 1998; Wunsch and Ferrari, 2004]. However, the exact magnitude of the wind-induced power input to NI motions and the relative importance of tidal and wind forcing is under debate.

[3] The wind power input to NI motions has often been studied using realistic wind stress products but simplified ocean dynamics (slab ocean models), with varying estimates of the globally integrated rates: Alford [2001] found 0.3 TW. Watanabe and Hibiya [2002], who introduced an amplification factor for inertial current velocity, found 0.7 TW. Alford [2003] estimated 0.5 TW and attributed the former, larger result to an inadequate sea ice mask and a constant damping parameter. Plueddemann and Farrar [2006] pointed out that slab ocean models do not account for the energy lost due to vertical shear instability and therefore may systematically overestimate the wind work. Furthermore, slab ocean models miss the energy radiating into the deep ocean [Furuichi et al., 2008]. Using an Ocean General Circulation

\footnotetext{
${ }^{1}$ Max Planck Institute for Meteorology, Hamburg, Germany.

${ }^{2}$ International Max Planck Research School, Hamburg, Germany.

${ }^{3}$ Institut für Meereskunde, Universität Hamburg, Hamburg, Germany.

Corresponding author: A. Rimac, Max Planck Institute for Meteorology, Bundesstrasse 53, 20146 Hamburg, Germany. (antonija.rimac@zmaw.de)

(C)2013. American Geophysical Union. All Rights Reserved. 0094-8276/13/10.1002/grl.50929
}

Model (OGCM) with the vertical mixing scheme by Mellor [2003] and forced with 6-hourly wind stress field, Furuichi et al. [2008] estimated 0.4 TW, while Simmons and Alford [2012] recently found a global wind-generated power input of $0.4 \mathrm{TW}$ using an OGCM with a shear-driven entrainment scheme [Jackson et al., 2008] and a refined bulk mixed layer scheme [Hallberg, 2003].

[4] The wind power input to NI motions, for slab ocean models, is sensitive to the resolution of the wind stress field. For instance, Jiang et al. [2005] used 6-hourly wind stress fields and found an increase in the kinetic energy flux with increasing horizontal resolution. However, Klein et al. [2004] pointed out the importance of temporal resolution by showing a $20 \%$ decrease in the NI energy integrated over the water column when wind stress fields are changed from 3- to 6-hourly mean values. D'Asaro [1985] and Niwa and Hibiya [1999] showed that insufficient time resolution of the wind stress field may lead to aliasing errors.

[5] These different estimates indicate the need for systematically reconsidering the wind power input using a realistic OGCM and wind stress fields at higher time and space resolutions. We use the Max Planck Institute Ocean Model (MPIOM) with two different wind stress forcing: one from the National Centers for Environmental Prediction (NCEP) reanalysis and one from the Climate Forecast System Reanalysis (CFSR). We address the following questions: Is the kinetic energy of NI motions enhanced when highresolution wind stress forcing fields are used? If so, is this due to a higher level of overall wind variability or due to a better spatial or temporal resolution of the wind forcing? And finally, what is the magnitude of the wind power input to NI motions?

\section{The Ocean Model and the Experiments}

[6] MPIOM [Marsland et al., 2003] is a global OGCM based on the primitive equations, thus including the hydrostatic and Boussinesq approximation [Olbers et al., 2012]. It has about $0.4^{\circ}$ resolution and 40 levels. A primitive equation model can correctly simulate long NI motions that fall into the hydrostatic regime [Gill, 1982; Simmons and Alford, 2012]. Nonhydrostatic effects on gravity waves with wavelength at our model resolution remain small, even in the deep ocean at weak stratification. However, for a better simulation of the vertical propagation of the NI waves, higher spatial resolution of the model is necessary. MPIOM uses the Richardson number-dependent mixing scheme [Pacanowski and Philander, 1981]. It also includes an additional parametrization for the wind-induced stirring, which is a function of local $10 \mathrm{~m}$ wind speed, it decays exponentially with depth, and depends on the local static stability. The mixing scheme provides a more realistic dissipation of 
NI energy in the upper ocean and a more realistic simulation of the Mixed Layer Depth (MLD) than a slab ocean model with a simple Rayleigh drag does. The simulated mean MLD is in broad agreement with that derived from Polar Science Center Hydrographic Climatology (PHC) [Steele et al., 2001] (not shown). Jochum et al. [2013] showed that NI waves induce MLD deepening. On the other hand, the MLD in our model does not depend on NI motions. Therefore, the strength of NI motions, which depends on the resolution of the wind forcing, does not significantly change the MLD.

[7] A series of experiments are performed by driving MPIOM with the same surface fluxes of heat and fresh water but different wind stress forcing (Table 1). The heat and fresh water (precipitation minus evaporation) fluxes are derived from the 6-hourly NCEP reanalysis on T63 grid $\left(1.875^{\circ}\right.$ resolution) [Kalnay et al., 1996]. The fresh water flux is supplemented by daily river discharges on T106 grid $\left(1.125^{\circ}\right.$ resolution). Experiment NCEP is forced by 6-hourly wind stress on T63 grid [Kalnay et al., 1996]. Experiment CFSR is forced by 1-hourly wind stress on T383 grid $\left(0.35^{\circ}\right.$ resolution) [Saha et al., 2010]. The remaining experiments are divided into two sets. The first set (experiment TFX: TF04, TF06, TF12, and TF24) uses the CFSR wind stress field at its original spatial resolution but tem-
Table 1. Experiment Name, Temporal and Spatial Resolution of the Wind Stress Data Used to Force the Ocean Model MPIOM

\begin{tabular}{cccc}
\hline & Experiment Name & Temporal Resolution & Spatial Resolution \\
\hline & NCEP & 6-hourly & T63 grid \\
& CFSR & 1-hourly & T383 grid \\
& TF04 & 4-hourly & T383 grid \\
& TF06 & 6-hourly & T383 grid \\
TFX: & TF12 & 12-hourly & T383 grid \\
& TF24 & daily & T383 grid \\
& SF0.7 & 1-hourly & $0.7^{\circ}$ grid \\
& SF1.1 & 1-hourly & $1.125^{\circ}$ grid \\
SFX: & SF1.8 & 1-hourly & $1.875^{\circ}$ grid \\
& SF2.8 & 1-hourly & $2.8^{\circ}$ grid \\
\hline
\end{tabular}

porally filtered by sampling the CFSR wind stress every 4 , 6,12 , and $24 \mathrm{~h}$, respectively. The second set (experiment SFX: SF0.7, SF1.1, SF1.8, and SF2.8) uses the CFSR wind stress field at its original temporal resolution but spatially filtered to a coarser grid using nearest neighbor interpolation. The resulting wind stress fields have resolutions of about $0.7^{\circ}, 1.125^{\circ}, 1.875^{\circ}$, and $2.8^{\circ}$, respectively. These filters (subsampling and nearest neighbor) essentially preserve the total variance of the CFSR winds [von Storch et al.,

(a) Experiment NCEP

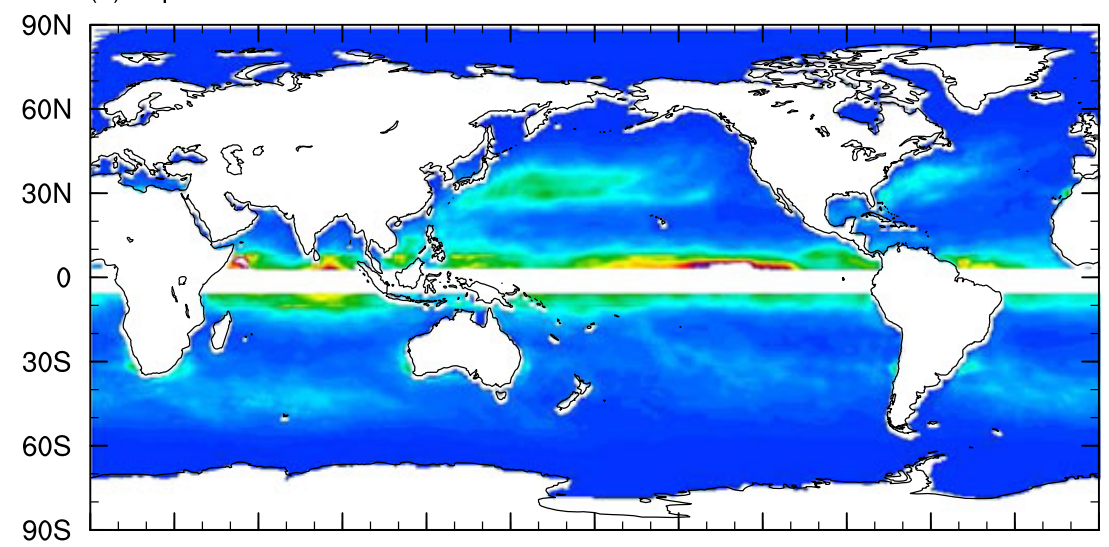

(b) Experiment CFSR

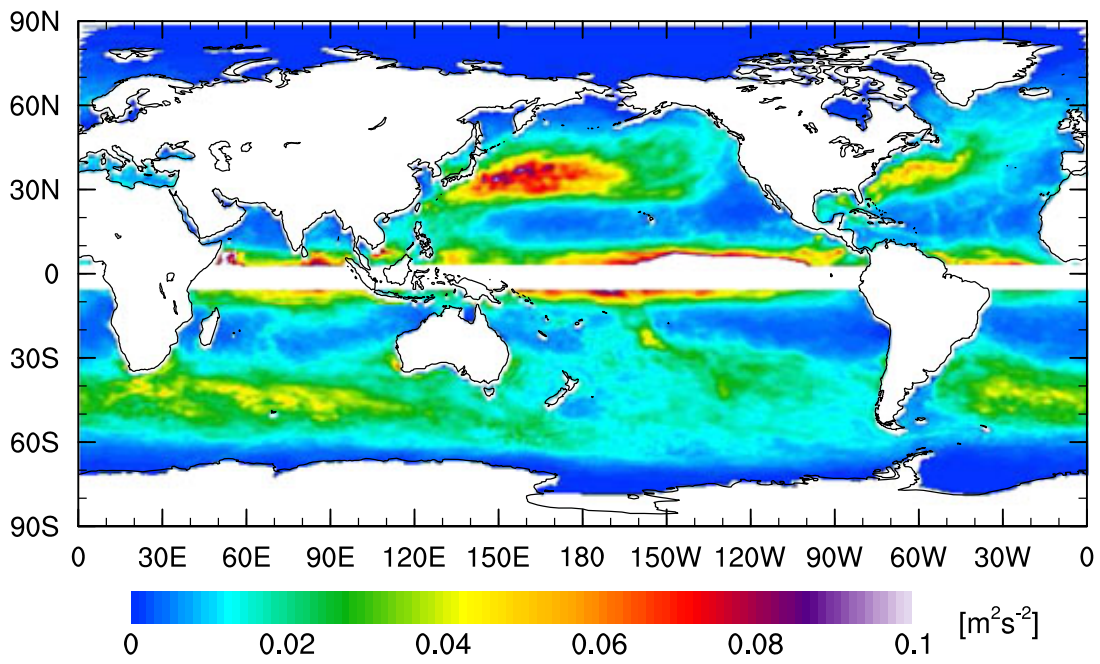

Figure 1. Spatial distribution of the near-inertial (NI) kinetic energy calculated from the bandpass-filtered model velocities taken from experiments (a) NCEP and (b) CFSR in $\mathrm{m}^{2} \mathrm{~s}^{-2}$. 

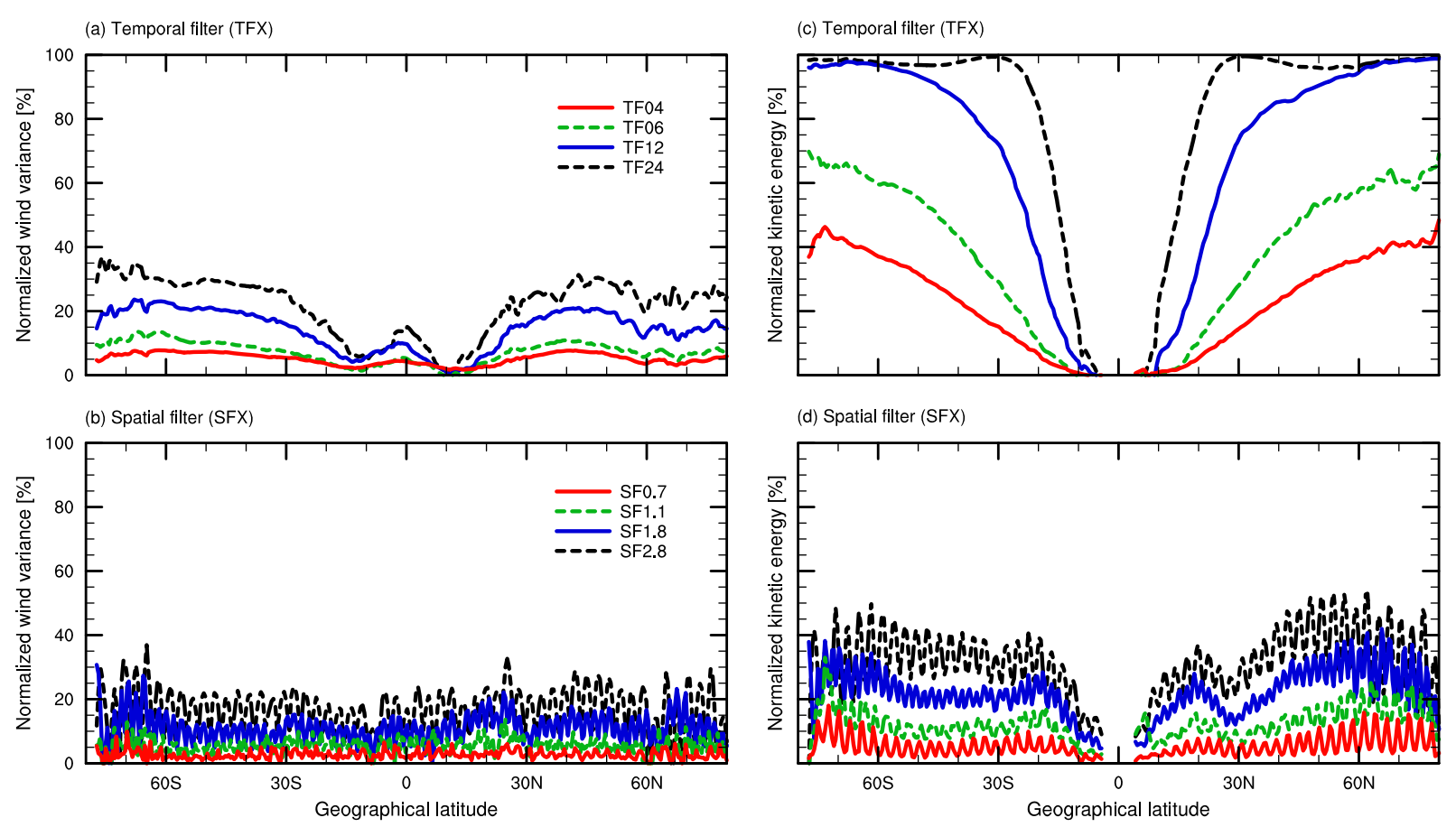

Figure 2. (left) Zonal mean difference in wind stress variance between experiment CFSR and experiments (a) TFX and (b) SFX normalized by the respective wind stress variance in experiment CFSR. (right) Zonal mean difference in the nearinertial kinetic energy between experiment CFSR and experiments (c) TFX and (d) SFX normalized by the near-inertial kinetic energy from experiment CFSR.

2007, appendix], allowing a better comparison of experiments SFX with experiments TFX. The different forcing fields are linearly interpolated in space using weighted averages of the four nearest grid points to the model grid and in time from the reanalysis to the model time step of $1 \mathrm{~h}$. The reduction of wind stress variance in experiments TFX and SFX, relative to experiment CFSR, is shown in Figures 2a and $2 \mathrm{~b}$. In all experiments, variance changes due to the differently filtered winds are moderate and mostly below $30 \%$. Two features are evident. First, the variance changes in wind stress field are larger in experiments TFX than in experiments SFX. Second, for experiments TFX, the variance changes are larger at the midlatitudes and high latitudes than in the tropical and subtropical regions.

[8] Although we make a separation in spatial and temporal variations of the wind field, it is possible that small-scale features, after being advected by the mean wind, appear as temporal variability. Our filtering method cannot separate such different sources of variability. By filtering out the spatial or the temporal variations in the wind forcing and allowing the ocean to freely respond to this, we are only able to assess the relative importance of temporal and spatial variations of winds in generating NI motions in the ocean, regardless of their generation mechanism. The experiments are carried out for the period of 2004 to 2005 . Hourly output is stored. For the analysis we use the last year (2005) and first-model level (at $6 \mathrm{~m}$ ).

\section{Results}

[9] The kinetic energy of NI motions is estimated as the variance of the anticyclonically rotating velocity vector at frequency, $\omega$, defined as $0.7 f<\omega<1.3 f$, where $f$ denotes the local inertial frequency. We choose this frequency range to be consistent with the study of Furuichi et al. [2008]. We concentrate on anticyclonically rotating variance, because it is a key feature of near-inertial motions. The calculation is done for each 3 month season of 2005, and the seasonal average is presented in Figure 1.

[10] In experiments NCEP and CFSR, the NI kinetic energy (Figure 1) shows a pronounced maximum around $35^{\circ}-50^{\circ}$ in the midlatitude storm tracks, consistent with Alford [2001], Watanabe and Hibiya [2002], Alford [2003], Furuichi et al. [2008], Simmons and Alford [2012], and Jochum et al. [2013]. The maximum along $30^{\circ}$ is a result of a strong daily cycle in the buoyancy forcing.

[11] Forcing the ocean model with higher-resolution wind stresses causes the NI kinetic energy to increase (Figure 1b versus Figure 1a). The globally averaged value increases from $0.006 \mathrm{~m}^{2} \mathrm{~s}^{-2}$ in experiment NCEP to $0.02 \mathrm{~m}^{2} \mathrm{~s}^{-2}$ in experiment CFSR. The increased values are comparable to the local observational estimates at the five positions found by Plueddemann and Farrar [2006]. Furthermore, the magnitude of the NI kinetic energy and the global mean NI velocity is comparable to observations by Chaigneau et al. [2008] and Elipot and Lumpkin [2008] (not shown).

[12] We analyze experiments TFX and SFX to understand the cause of the differences in NI energy levels between experiments CFSR and NCEP. Relative to experiment CFSR, the reduction in NI kinetic energy increases under increasingly strong filtering in time and space of the wind stress field (Figures $2 \mathrm{c}$ and $2 \mathrm{~d}$ ). When normalized by the NI energy in experiment CFSR, wind stress forcing sampled every $4 \mathrm{~h}$ (TF04) generates $40 \%$ less kinetic energy at high latitudes than hourly wind stress forcing does. Using a very coarse temporal filter, TF24, the NI kinetic energy 


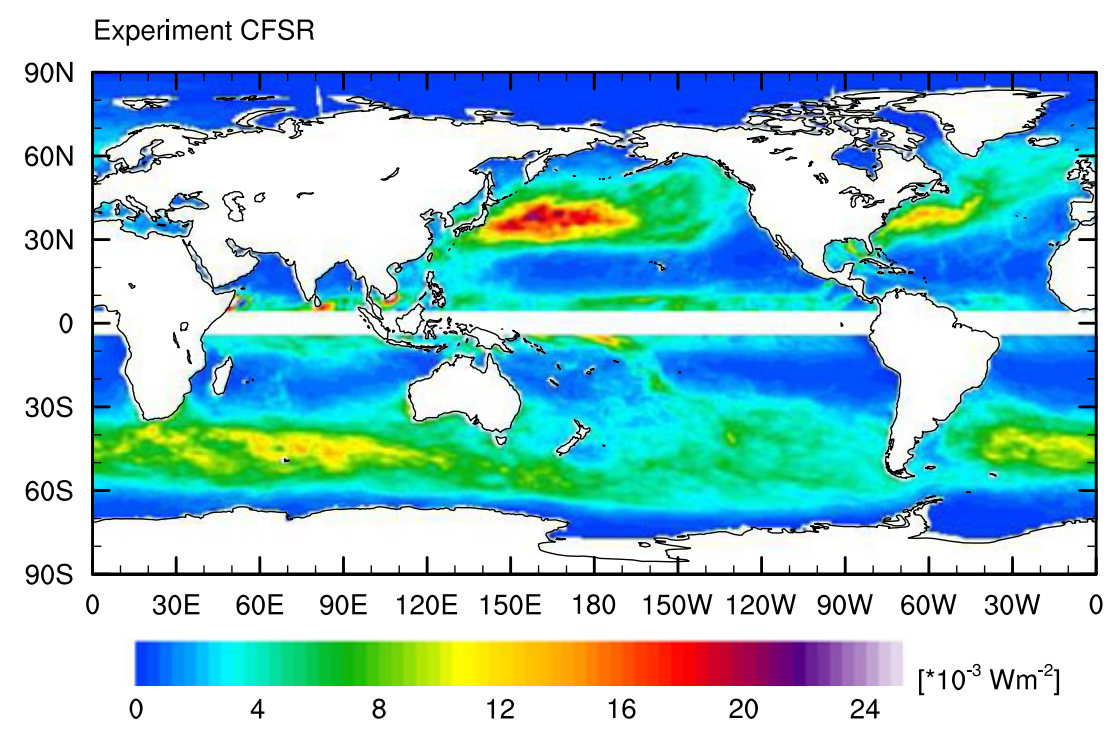

Figure 3. Spatial distribution of the wind power input to near-inertial (NI) motions calculated as the cross-spectrum between current velocities and wind stress and integrated over the NI frequency range in $* 10^{-3} \mathrm{Wm}^{-2}$. A Daniell estimator is used to estimate the cross-spectrum [von Storch and Zwiers, 1999]. Note that the method based on the integrated cross-spectrum (defined by a raw cross-periodogram) is identical to the method based on data filtered in respect to the same frequency range.

decreases by $84 \%$ on average and the decrease reaches about $100 \%$ poleward of $30^{\circ}$, meaning that NI motions are entirely filtered out there. The reduction in NI kinetic energy induced by spatially filtered wind stress fields is much more moderate. The results indicate that temporal scales of the wind stress play a more important role in generating NI motions than spatial scales.

[13] The dominance of temporal scales over spatial scales results from the fact that the time rate of change of NI motions is forced by the winds so that the spectrum of the velocity $\Gamma_{\text {vel }}(\omega)$ and that of wind stress $\Gamma_{\tau}(\omega)$ in the absence of friction satisfies

$$
\Gamma_{\mathrm{vel}}(\omega) \sim \frac{\Gamma_{\tau}(\omega)}{(\omega+f)^{2}},
$$

with a resonance at the inertial frequency, $\omega=-f$. In experiment TF24, wind stress variations on time scales shorter than $24 \mathrm{~h}$ are strongly suppressed. Consequently, $\Gamma_{\tau}(\omega)$ essentially vanishes for $|\omega|>1 / 24$ cycles per hour and no significant inertial kinetic energy is excited poleward of $30^{\circ}$ latitudes. In experiments TF12, TF06, and TF04, the amplitude

Table 2. Experiment Name and Globally Integrated Windgenerated Power Input to NI Motions

\begin{tabular}{lcc}
\hline & Experiment Name & Wind Power Input (TW) \\
\hline & NCEP & 0.3 \\
& CFSR & 1.1 \\
& TF04 & 0.9 \\
TFX: & TF06 & 0.7 \\
& TF12 & 0.4 \\
& TF24 & 0.2 \\
SFX: & SF0.7 & 1.0 \\
& SF1.1 & 1.0 \\
& SF1.8 & 0.9 \\
\hline
\end{tabular}

of $\Gamma_{\tau}(\omega)$ at $|\omega|>1 / 24$ cycles per hour increases noticeably poleward of $30^{\circ}$ latitudes. The resonance response, which results in finite inertial kinetic energy in the presence of friction, becomes increasingly evident. Similar resonance behavior cannot be identified for wave number spectra.

[14] Finally, we calculate the wind power input to NI motions using the cross-spectrum between velocity and wind stress integrated over the NI frequency range $(0.7 f<\omega<$ $1.3 f$ ). The spatial distribution of the wind power input to NI motions (Figure 3 ) reaches maximum of about $0.02 \mathrm{~W} / \mathrm{m}^{2}$ in the storm track regions in experiment CFSR. Integrated globally, this value amounts to $1.1 \mathrm{TW}$ (Table 2). The latter value is more than three times higher than in experiment NCEP $(0.3 \mathrm{TW})$. The power input in the experiments TFX and SFX decreases with coarser resolution, but the decrease is more pronounced in experiments TFX.

\section{Discussion and Conclusions}

[15] In this study, we address the influence of wind stress forcing on the generation of near-inertial (NI) motions in the ocean by driving a global eddy-permitting OGCM with the same fluxes of heat and fresh water but with wind stress of different spatial and temporal resolutions. The NI kinetic energy increases with increasing resolution in wind stress forcing (Figure 1). Its area-averaged value is three times higher (up to a factor four in the storm track regions) in experiment CFSR (forced by high-resolution wind stress: 1hourly wind stress on T383 grid) than in experiment NCEP (forced by low-resolution wind stress: 6-hourly wind stress on T63 grid). The wind power input to NI motions is 1.1 TW in experiment CFSR, which is three times higher than in experiment NCEP (Table 2). Time filtering of the CSFR data affects the NI kinetic energy stronger than space filtering of the same data (Figure 2). This suggests that high-frequency 
temporal variations in the wind stress field are more efficient in generating NI wave energy than small-scale spatial variations in the wind stress field.

[16] The impact of the resolution of the wind forcing has been studied using a slab ocean model by Klein et al. [2004] who attributed their findings to better temporal resolution of the wind stress field, while Jiang et al. [2005] stressed the importance of horizontal resolution. On the other hand, we analyze combinations of different spatial and temporal resolutions using an OGCM and attribute the increased wind power input to the better temporal resolution of the CFSR winds compared to the NCEP winds. To conclude, there is a strong sensitivity of the wind power input to NI motions relative to the resolution of the wind stress forcing. This points to a possible underestimation of the energy available for the deep ocean mixing and a need for improved estimates using more sophisticated ocean models and wind stress fields at higher spatial and temporal resolutions.

[17] Acknowledgments. We thank J. Metzger for the CFSR wind data. Numerical computations were performed on the German Climate Computer Center (DKRZ). We acknowledge the comments of Chiel van Heerwaarden.

[18] The Editor thanks three anonymous reviewers for their assistance in evaluating this paper.

\section{References}

Alford, M. H. (2001), Inertial swell generation: The spatial distribution of energy flux from the wind to mixed layer near-inertial motions, J. Phys. Oceanogr., 31, 2359-2368.

Alford, M. H. (2003), Improved global maps and 54-year history of wind-work on ocean inertial motions, Geophys. Res. Lett., 30(8), 1424, doi:10.1029/2002GL016614.

Chaigneau, A., O. Pizarro, and W. Rojas (2008), Global climatology of near-inertial current characteristics from Lagrangian observations, Geophys. Res. Lett., 35, L13603, doi:10.1029/2008GL034060.

D'Asaro, E. A. (1985), The energy flux from the wind to near-inertial motions in the surface mixed layer, J. Phys. Oceanogr., 15, 1043-1059.

Elipot, S., and R. Lumpkin (2008), Spectral description of oceanic near-surface variability, Geophys. Res. Lett., 30, L05606, doi:10.1029/ 2008GL032874

Furuichi, N., T. Hibiya, and Y. Niwa (2008), Model-predicted distribution of wind-induced internal wave energy in the world's oceans, J. Geophys. Res., 113, C09034, doi:10.1029/2008JC004768.

Gill, A. E. (1982), Atmosphere-Ocean Dynamics, 662 pp., Academic Press, London.

Hallberg, R. (2003), The ability of large-scale ocean models to accept parameterizations of boundary mixing, and a description of a refined bulk mixed-layer model. Internal gravity waves and small-scale turbulence, in Proceedings of the 'Aha Huliko'a Hawaiian Winter Workshop, edited by P. Müller, pp. 187-203, Hawaii Institute of Geophysics Special Publication, University of Hawaii.

Jackson, L. R., R. Hallberg, and S. Legg (2008), A parametrization of shear-driven turbulence for ocean climate models, J. Phys. Oceanogr. 39, 1756-1775, doi:10.1175/2009/JPO4085.1.

Jiang, J., Y. Lu, and W. Perrie (2005), Estimating the energy flux from the wind to ocean inertial motions: The sensitivity to surface wind fields, Geophys. Res. Lett., 32, L15610, doi:10.1029/2005GL023289.

Jochum, M., B. P. Briegleb, G. Danabasoglu, W. G. Large, S. R. Jayne, M. H. Alford, and F. O. Bryan (2013), On the impact of oceanic nearinertial waves on climate, J. Clim., 26, 2833-2844, doi:10.1175/JCLI-D12-00181.1.

Kalnay, E., et al. (1996), The NCEP/NCAR 40-year reanalysis project, Bull. Am. Meteorol. Soc., 77, 437-470.

Klein, P., G. Lapeyre, and W. G. Large (2004), Wind ringing of the ocean in presence of mesoscale eddies, Geophys. Res. Lett., 31, L15306, doi:10.1029/2004GL020274.

Marsland, S. J., H. Haak, J. H. Jungclaus, Latif M., and F. Röske (2003), The Max-Planck-Institute global ocean/sea ice model with orthogonal curvilinear coordinates, Ocean Modell., 5, 91-127.

Mellor, G. L. (2003), Users Guide for a Three-dimensional, Primitive Equation, Numerical Ocean Model, 53 pp., Prog. in Atmos. and Ocean. Sci., Princeton University.

Munk, W. (1981), Internal waves and small-scale processes, in Evolution of Physical Oceanography, edited by B. A. Warren C. Wunsch, pp. 264-291, MIT Press, Cambridge, MA.

Munk, W., and C. Wunsch (1998), Abyssal recipes II: Energetics of tidal and wind mixing, Deep Sea Res., 45, 1977-2010.

Niwa, T., and T. Hibiya (1999), Response of the deep ocean internal wave field to traveling midlatitude storms as observed in long-term current measurements, J. Geophys. Res., 104(C5), 10,981-10,989.

Olbers, D., J. Willebrand, and C. Eden (2012), Ocean Dynamics, 704 pp., Springer, Heidelberg.

Pacanowski, R. C., and S. G. H. Philander (1981), Parametrization of vertical mixing in numerical models of tropical oceans, J. Phys. Oceanogr. $11,1443-1451$.

Plueddemann, A. J., and J. T. Farrar (2006), Observations and models of the energy flux from the wind to mixed-layer inertial currents, Deep Sea Res., 53, 5-30.

Saha, S., et al. (2010), The NCEP climate forecast system reanalysis, Bull. Am. Meteorol. Soc., 91, 1015-1057, doi:10.1175/2010BAMS3001.1.

Simmons, H. L., and M. H. Alford (2012), Simulating the long-range swell of internal waves generated by ocean storms, Oceanography, 25 (2), 30-41, doi:10.5670/oceanog.2012.39.

Steele, M., R. Morley, and W. Ermold (2001), PHC: A global ocean hydrography with a high quality Arctic Ocean, J. Clim., 14, 2079-2087.

von Storch, J.-S., H. Sasaki, and J. Marotzke (2007), Wind-generated power input to the deep ocean: An estimate using a $1 / 10^{\circ}$ general circulation model, J. Phys. Oceanogr., 37(3), 657-672, doi:10.1175/ JPO3001.1.

von Storch, H., and F. W. Zwiers (1999), Statistical Analysis in Climate Research, 484 pp., Cambridge Univ. Press, Cambridge, U. K.

Watanabe, M., and T. Hibiya (2002), Global estimates of the wind-induced energy flux to inertial motions in the surface mixed layer, Geophys. Res. Lett., 29(8), 1239, doi:10.1029/2001GL014422.

Wunsch, C., and R. Ferrari (2004), Vertical mixing, energy, and the general circulation of the oceans, Annu. Rev. Fluid Mech., 36, 281-314. 